\title{
Pitaya-Like Carbon Nanofiber Sulfur Composites as Promising Cathode Materials for High-Performance Li-S Batteries
}

\author{
Yanhua Wang ${ }^{1}$, Jianying Tong ${ }^{1}$, Kefeng Xie ${ }^{2, *}$ \\ ${ }^{1}$ College of Biology and Environmental Engineering, Zhejiang Shuren University, Hangzhou 310000, \\ China \\ ${ }^{2}$ State Key Laboratory of Plateau Ecology and Agriculture, Qinghai University, Xining 810016, China \\ *E-mail: xiekefeng@qhu.edu.cn
}

doi: $10.20964 / 2018.09 .54$

Received: 5 June 2018 / Accepted: 11 July 2018 / Published: 5 August 2018

\begin{abstract}
First, carbon nanofibers were prepared by electrospinning. Then, a CN/S composite was prepared by melting elemental sulfur via high-temperature heat treatment. Using the prepared CN/S composite as the cathode material, a lithium sulfur battery was made from the cathode material. The initial discharge capacity of the CN/S battery reached $1116 \mathrm{mAh} \mathrm{g}^{-1}$, the utilization ratio of sulfur was $73 \%$, and the specific capacity was kept at $810 \mathrm{mAh} \mathrm{g}^{-1}$ after 100 cycles. The electrochemical performance of the $\mathrm{CN} / \mathrm{S}$ composite was significantly higher than that of the elemental sulfur. It is shown that the lithium sulfur electricity can be effectively promoted by the CN/S composite.
\end{abstract}

Keywords: Carbon nanofiber, CN/S composite, cathode, Li-S battery.

\section{$\underline{\text { FULL TEXT }}$}

(C) 2018 The Authors. Published by ESG (www.electrochemsci.org). This article is an open access article distributed under the terms and conditions of the Creative Commons Attribution license (http://creativecommons.org/licenses/by/4.0/). 